\title{
Use of electrophoresis technique to study removal of toxic metal ions from waste water by adsorption on mineral surface
}

\author{
S. E. Elmofty \\ Department of Mining, Petroleum and Metallurgical Engineering, \\ Cairo University, Egypt
}

\begin{abstract}
Electrophoresis technique is used to investigate the sorption possibility of toxic metal ions from aqueous solutions on clay minerals. Removal of heavy metals such as cobalt, nickel, lead and cadmium from waste water was investigated. Electrophoresis tests were performed as a function of $\mathrm{pH}$ for different heavy metal cations to identify the mode and extent of interactions of adsorption in the system. The adsorption isotherms and $\mathrm{pH}$ effect indicate that adsorption of metal ions increase in the order of $\mathrm{Co}<\mathrm{Ni}<\mathrm{Cd}<\mathrm{Pb}$.

Keywords: electrophoresis, toxic heavy metals, adsorption, electrical double layer.
\end{abstract}

\section{Introduction}

Nowadays, large quantities of metals and pollutants that are currently entering the environment from various sources, thus, alternative methods to filter wastewater are being studied. The interest towards finding cheaper and more efficient adsorbents has created a surge in the amounts of research to be conducted about adsorption. One of these areas of research focused upon cation exchange phenomena. Mineral, such as clay, can absorb wastes from water (e.g. Kara et al. [1]). Clay and sepiolite, both members of the palygorskite family, are two such clays that adsorb metal cations from solutions.

Crystal structure, chemical composition, exchanging cations and small crystal lattice size are responsible for much unique prosperity such as, large chemically 
active surface area, high cation exchange capacity and big hydration affinity. (e.g. Haden and Schwint [2], Haden [3] and Elmofty [4]).

The extremely large surface area of Clay, approximately $155 \mathrm{~m}^{2} / \mathrm{g}$, makes it very sorptive in its natural form. Both external and internal structures contribute to this surface area. The internal bundles, or haystacks, aid the external surface area in achieving great amounts of adsorption. Clay can take in water up to $200 \%$ of its own weight. During calcinations, the haystack structure of the Clay becomes very porous. The pore volume is about $0.6 \mathrm{ml} / \mathrm{g}$ and pore diameter is about 200 A. The creation of this porous structure is believed to be more important to the sorptive capability than the high surface area of clay (e.g. McCarter et al. [5]). Many studies have been done on the selective adsorption by attapulgite. The order of sorptivity is suggested to be as follows: water $>$ alcohols $>$ acids $>$ aldehydes $>$ ketones $>$ n-olefins $>$ neutral esters $>$ aromatics $>$ cycloparaffins $>$ paraffins (e.g. Karston [6]).

The adsorption of surface active agents at the interface of a solid and liquid phase is a fundamentally important phenomenon. The adsorption is controlled by the chemical nature of the species being adsorbed and also the sub state Zeta potential is the difference between the potential at the slip plane and the potential in the bulk solution. Zeta potential is the most easily accessible parameter to experimentally determine the sign and magnitude of the potential at the solid liquid interface (e.g. Hiemenz [7], Hanna and Somasundaran [8]).

\section{Experimental}

\subsection{Materials}

The Clay sample used in this study has been collected from Alex, Egypt. The sample was grounded to minus 80 microns; chemical analysis was performed by atomic adsorption (AA). Table 1 represents the sample. The surface area of Clay was found to be $155 \mathrm{~m}^{2} / \mathrm{g}$ by means of BET method using nitrogen as adsorbent. The measurements were repeated on three samples and the average was reported.

Table 1: $\quad$ Main chemical composition of Clay.

\begin{tabular}{|c|c|}
\hline Compound & \% by weight \\
\hline $\mathrm{SiO}_{2}$ & 55.5 \\
$\mathrm{Al}_{2} \mathrm{O}_{3}$ & 19.4 \\
$\mathrm{MgO}$ & 1.34 \\
L.O.I & 11.2 \\
\hline
\end{tabular}

\subsection{Methods}

\subsubsection{Electro kinetic characterization}

The zeta potential of Clay particles exposed to various chemical environments was measured using the zeta meter. There are two basic mechanisms that contribute in the development of charge on the surface of mineral particles in 
aqueous solution. The first is associated with the dissolution of inorganic groups on the mineral surface; the other is the specific adsorption of ions from the solution phase. Zeta-Meter 3.0 was used in the study. This instrument measures Zeta Potential values by computing the electrophoretic mobility, considering other physical measurements and constants such as: viscosity, dielectric constant and ionic strength. Suspension is first placed in the electrophoresis cell. $\mathrm{KNO}_{3}$ was used as an indifferent electrolyte $\left(2 \times 10^{-3} \mathrm{M} / \mathrm{L}\right)$. Then, electrodes are inserted and the cell is placed on the mirrored cell holder, which reflects the light beam from the illuminators upward, through the cell tube. Only reflected light from each suspended particle is seen. The Zeta Meter measures the elapsed time then combines the data with the tracking voltage and computes the Zeta Potential based on the Smoluchowski Equation. The Zeta potential was measured after conditioning. The mineral particles conditioned in water in the absence and presence of inorganic heavy metal $\left(10^{-3} \mathrm{M} / \mathrm{L}\right)$ concentration, $\mathrm{pH}$ was adjusted, and then zeta potential was measured using a zeta meter model ZM3-83.

\subsubsection{Adsorption kinetics}

In the experiments of batch kinetic adsorption, $1 \mathrm{~g}$ of clay was placed in heavy metal stock solution $\left(10^{-2} \mathrm{M} / \mathrm{L}\right)$ in $100 \mathrm{ml}$ volumetric flask and shaken by a horizontal bench shaker at constant temperature, $298^{\circ} \mathrm{K}$. After specific time, samples were removed from the shaker and their residual concentrations were determined. The kinetic curve was plotted of the adsorption of each sample as a function of time. The equilibrium time was determined and used in adsorption isotherm experiments.

\subsubsection{Adsorption isotherm}

Adsorption experiments were conducted using $1 \mathrm{~g}$ dry sample of Clay mineral and the heavy metal ions of $\mathrm{Co}^{+2}, \mathrm{Ni}^{+2}, \mathrm{~Pb}^{+2}, \mathrm{Cd}^{+2}$. The heavy metal stock solution $\left(10^{-2} \mathrm{M} / \mathrm{L}\right)$ was prepared by dissolving $\mathrm{CoCl}_{2}, \mathrm{NiCl}_{2}, \mathrm{CdCl}_{2}$ and $\mathrm{Pb}$ $\left(\mathrm{NO}_{3}\right)_{2}$ (Fisher Grade) in the deionizer water and shacked. For the purpose of this study, the air-dried Clay was not subjected to any further pretreatment procedures. All experiments were conducted at room temperature. The solid to liquid ratios, conditioning time, and effect of solution $\mathrm{pH}$, and effect of heavy metal ions concentration on adsorption were studied.

The $\mathrm{pH}$ was adjusted. The solution was shaken for equilibrium time at $298^{\circ}$ $\mathrm{K}$. At the end of the adsorption period, the samples were centrifuged at 10,000 $\mathrm{rpm}$ for 15 minutes to separate supernatant from the settled fraction. The adsorption density at equilibrium $q_{\mathrm{e}}\left(\mathrm{g} / \mathrm{m}^{2}\right)$ was calculated according to eqn. (1):

$$
q_{e}=\frac{\left(C_{o}-C_{e}\right) V}{W \times \sigma}
$$

where $C_{0}$ and $C_{\mathrm{e}}$ are the initial and equilibrium solution concentrations $\left(\mathrm{g} / \mathrm{m}^{3}\right)$, respectively, $V$ the volume of the solutions $\left(\mathrm{m}^{3}\right)$ and $W$ the weight of collector used $(\mathrm{g}) . \sigma$ Is the specific surface area of the solids $\left(\mathrm{m}^{2} / \mathrm{g}\right)$, (e.g. Elmofty et al. [9]). 


\section{Results and discussion}

\subsection{Surface charge study}

The surface charge patterns of Clay mineral particles in the absence and presence of the chloride salts of the heavy metals were determined [Fig. 1]. By electrophoresis measurements (Zeta Potential) results show that Clay particles both in absence and presence of dissolved salts of heavy metals $\mathrm{Cd}, \mathrm{Cr}, \mathrm{Pb}$ and $\mathrm{Ni}$ were net negatively charged at $\mathrm{pH}$ values above there is isoelectric points (I.E.Ps). However a net positive charge (charge reversal) in the presence of $\mathrm{Cd}$ at $\mathrm{pH}$ values above 6 was observed. (e.g. Anderson and Rubin [10], Elmofty et al. [11]).

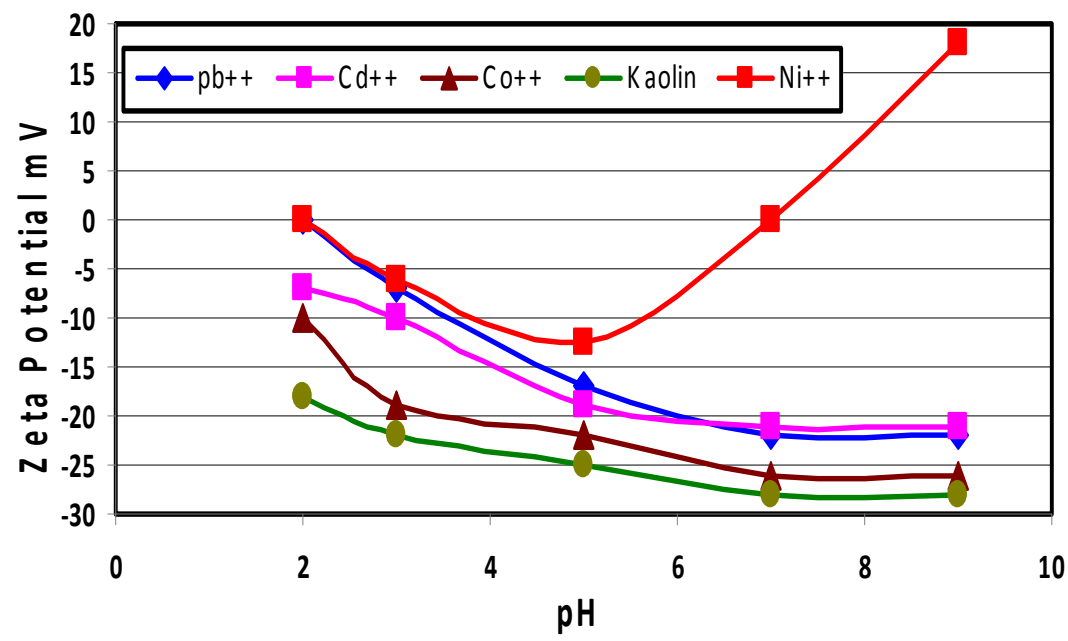

Figure 1: Zeta potential of clay particles in absence and presence of different heavy metal cations.

Most phyllosilicate minerals (as Clay) have permanent negative surface charges arising from nonstoichiometric isomorphism substitution of cations within their structures. Commonly, $\mathrm{Al}^{3+}$ substitutes for $\mathrm{Si}^{4+}$ in the tetrahedral sheet and $\mathrm{Mg}^{2+}$ for $\mathrm{Al}^{3+}$ in the dioctahedral sheet. The negative layer charges are exactly balanced by the adsorption of contentious; the charge of phyllosilicate layers is satisfied by the accumulation of cations in a diffuse layer at the surface and exclusion of anions from this surface region Fig. 2. The quantity of exchangeable cations held is usually expressed as the cation exchange capacity (CEC). Expansion is facilitated by exchangeable cations having a tendency to be highly hydrated in solution. Results indicated on (I.E.Ps) for clay of $\mathrm{pH}$ (1.4). The observed shifts of the (I.E.Ps) after additions of dissolved studied ions indicate a specific adsorption on the surface of clay, is presented in fig. 1 . 


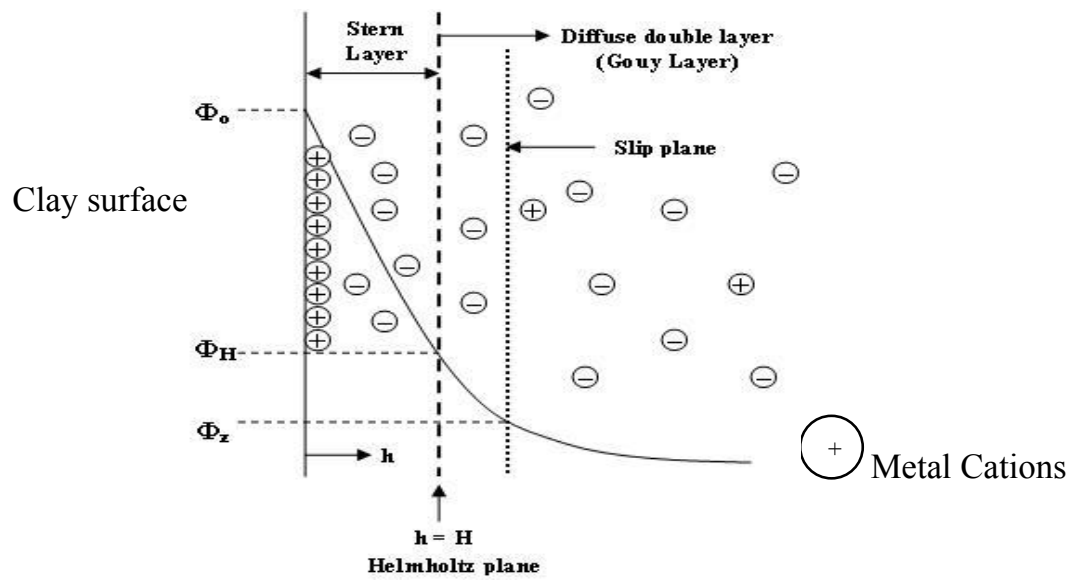

Figure 2: Illustration of the double-layer showing the surface of clays particles (left side), and the distribution of the adsorbed cations and anions within the double layer (right side).

\subsection{Adsorption kinetics}

The effect of the conditioning time on adsorption density of $\mathrm{M}^{2+}$ ions onto Clay is presented in Fig. 3.

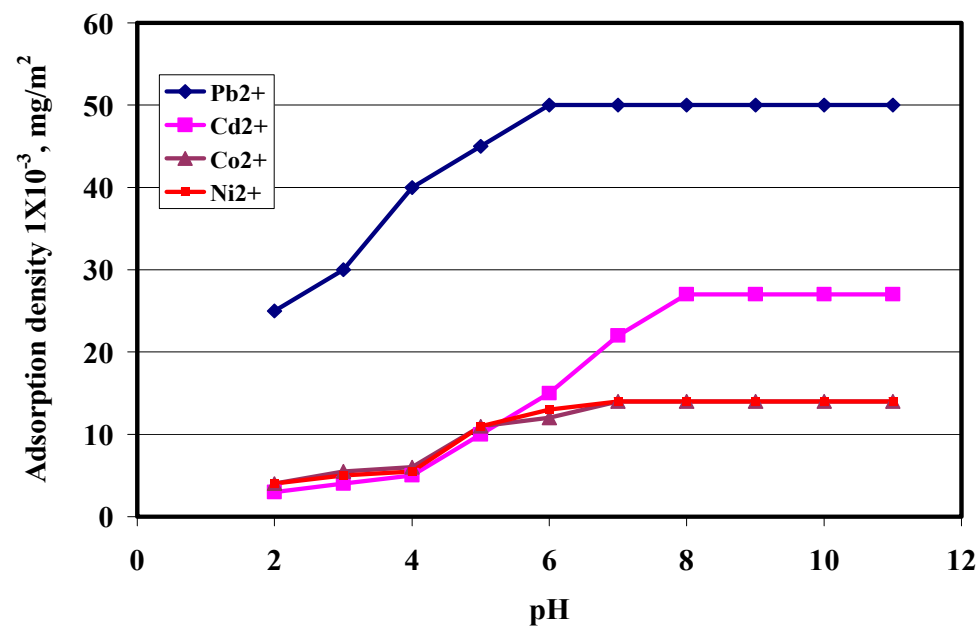

Figure 3: Effect of equilibrium time on adsorption density of $\mathrm{M}^{2+}$ onto Clay. $\left(\mathrm{S} / \mathrm{L} 50 \mathrm{~g} / \mathrm{L}, \mathrm{C}_{\mathrm{i}}=10^{-3} \mathrm{M} / \mathrm{L}\right.$, temperature $\left.20^{\circ} \mathrm{C}\right)$.

These experiments were performed in order to quantify the time required for complete adsorption of $\mathrm{M}^{2+}$ ions onto the sites of Clay. $50 \mathrm{~g} / \mathrm{L}$ solid to liquid suspensions were prepared and sufficient $\mathrm{M}^{2+}$ ions were added to the suspensions 
to produce several $\left(10^{-3} \mathrm{M} / \mathrm{L}\right)$ heavy metal solutions. The total volume of the mixture was adjusted to a $40 \mathrm{ml}$ volume. After a period of time ranging from 30 seconds to 24 hours, the suspensions were centrifuged at 10,000 rpm for 15 minutes. The supernatant was determined by Atomic adsorption spectrophotometer 2380 Perkin-Elmer. After subtracting the residual $\mathrm{M}^{2+}$ ions concentration $\left(\mathrm{C}_{\mathrm{r}}\right)$ from their initial concentration $\left(\mathrm{C}_{\mathrm{i}}\right)$, the adsorption density has been calculated. These experiments showed that $\mathrm{M}^{2+}$ ions adsorption onto Clay was a fast process. Over $87 \%$ of heavy metal ions adsorption is completed in the first 5 minutes. Therefore, the equilibrium time before the first 5 minutes is needed to be studied. Figure 3 presents the effect of equilibrium time ranging from 30 to 60 seconds on adsorption onto Clay.

The investigation of the adsorption rate controlling steps mandates testing experimental data by kinetic models. The pseudo first-order and pseudo secondorder models were used. The first-order model is generally expressed as follows (e.g. Yalcin [12]):

$$
\frac{d q_{t}}{d t}=k_{1}\left(q_{e}-q_{t}\right)
$$

where $q_{\mathrm{e}}$ and $q_{t}$ are the amounts of collector $(\mathrm{mg} / \mathrm{g})$ adsorbed on the clay mineral surface at equilibrium, and at time $t$, respectively and $k_{1}$ is the rate constant $\left(\mathrm{min}^{-1}\right)$. Integrating eqn. (2), at the following boundary conditions, $t=0$ and $q t$ $=0$ to $t=t$ and $q_{\mathrm{e}}=q t$ eqn. (2) becomes:

$$
\log \left(q_{e}-q_{t}\right)=\log q_{e}-\frac{k_{1}}{2.303} t
$$

On the other hand, the second-order equation was used to predict the behavior over the whole range of adsorption. The second-order rate equation is described by:

$$
\frac{d_{q_{t}}}{d t}=k_{2}\left(q_{e}-q_{t}\right)^{2}
$$

where $k_{2}$ is the rate constant of pseudo-second-order sorption (g/mg $\mathrm{min}$ ). Integrating eqn. (4) at the boundary conditions $t=0$ and $q t=0$ to $t=t$ and $q \mathrm{e}=q t$ eqn. (4) becomes:

$$
q_{t}=\frac{t}{\frac{1}{k_{2} q_{t}^{2}}+\frac{t}{q_{e}}}
$$

The constants $q_{\mathrm{e}}$ and $k_{2}$ can be determined using Excel Solver. The values of constants $q_{\mathrm{e}}$ and $k_{2}$ for second-order sorption were given in Table 2, (e.g. Elmofty et al. [9]). 
Table 2: $\quad$ Kinetic models constants for heavy metals adsorption on Clay.

\begin{tabular}{|c|c|c|c|c|c|}
\hline \multirow{2}{*}{$\begin{array}{c}\text { Model } \\
\text { type }\end{array}$} & $\begin{array}{c}\text { Model } \\
\text { constants }\end{array}$ & Heavy metals & \multicolumn{2}{|c|}{} \\
\cline { 3 - 5 } First order & $\mathrm{q}_{\mathrm{e}}$ & 0.02 & $\mathrm{Pd}$ & $\mathrm{Co}$ & $\mathrm{Ni}$ \\
& $k_{1}$ & 18.196 & 0.01 & 0.006 & 0.006 \\
& $\mathrm{q}_{\mathrm{e}}$ & 0.0228 & 0.0124 & 0.008 & 0.008 \\
Second & $k_{2}$ & 200 & 200 & 200 & 200 \\
order & &
\end{tabular}

\subsection{Solid to liquid (S/L) ratio}

In order to perform accurate $\mathrm{M}^{2+}$ adsorption experiments, the proper ratio of Clay weight to $\mathrm{M}^{2+}$ ions must be determined. Separate samples of dry Clay power ranging 0.4-8.0 $\mathrm{g}$ were weighed and placed in $60 \mathrm{ml}$ polyethylene bottles containing distilled water.

Clay was added to each $10^{-3} \mathrm{M} \mathrm{Co}^{+2}, \mathrm{Ni}^{+2}, \mathrm{~Pb}^{+2}, \mathrm{Cd}^{+2}$ solutions to obtain the appropriate solid to liquid ratio. For this experiment, five solid to liquid ratios were studied, i.e., $0.1,0.2,0.5,1$, and 2 in $10 \mathrm{ml}$ solution, respectively. Three samples of the $0.5 / 10 \mathrm{ml}$ solid to liquid ratio were prepared because this has been the preferred ratio in past experiments. Therefore, the accuracy of the $0.5 / 10 \mathrm{ml}$ solid to liquid ratio data was ensured by multiple samples. Once the samples were prepared, each was covered and stirred for six hours at a rate of 180 strokes per minute. After stirring, the samples were centrifuged at 10,000 rpm for 15 minutes and the clear supernatants were collected in vials for analysis.

The presence of residual $\mathrm{Co}^{+2}, \mathrm{Ni}^{+2}, \mathrm{~Pb}^{+2}, \mathrm{Cd}^{+2}$ adsorbed in the supernatant was determined using (AA).

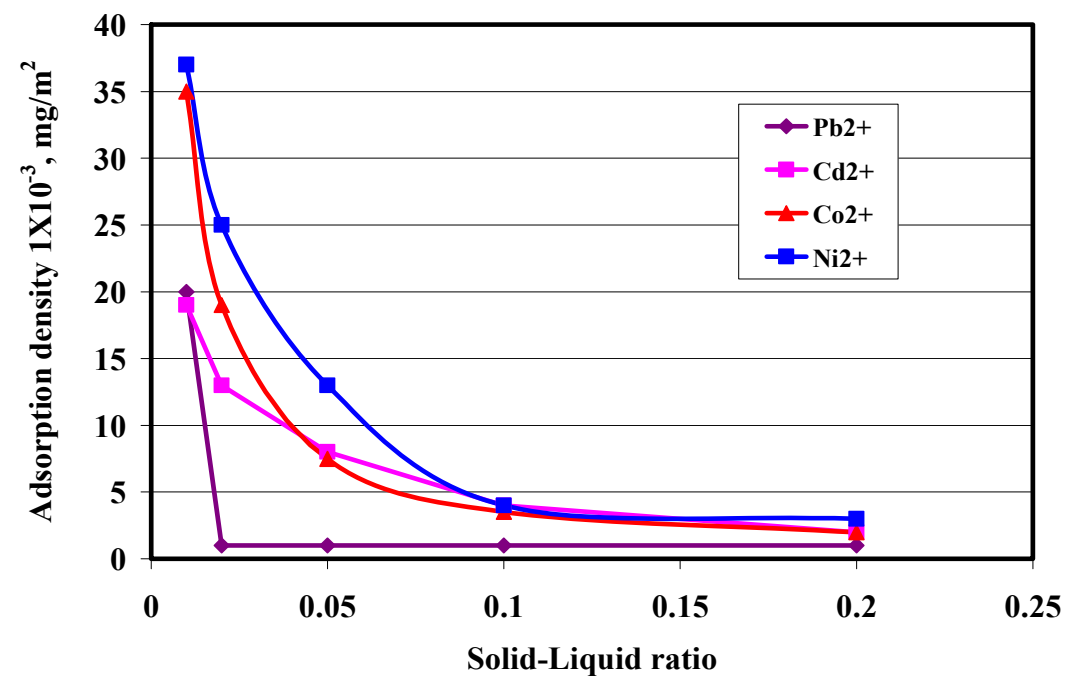

Figure 4: Effect of solid to liquid ratio on the adsorption of $\mathrm{M}^{2+}$ onto Clay (Conditioning time of $15 \mathrm{~min}, \mathrm{C}_{\mathrm{i}}=10^{-3} \mathrm{M} / \mathrm{L}$, Temperature $20^{\circ} \mathrm{C}$, and $\mathrm{pH}$ 5-8). 
The adsorption of $\mathrm{M}^{2+}$ onto Clay versus solid to liquid ratio is presented in Fig. 4. The adsorption density decreases as the solid concentration increases up to $50 \mathrm{mg} / \mathrm{ml}$ then decreases when the solid concentration rises above this value. The initial $\mathrm{M}^{2+}$ concentration for these experiments is $\left(10^{-3} \mathrm{M} / \mathrm{L}\right)\left(\mathrm{Co}^{2+}=58.98\right.$, $\mathrm{Ni}^{2+}=58.70, \mathrm{~Pb}^{2+}=207.0$ and $\left.\mathrm{Cd}^{2+}=112.41 \mathrm{ppm}\right)$ and the residual $\mathrm{M}^{2+}$ ions Concentration are $\mathrm{Co}^{2+}=0.27, \mathrm{Ni}^{2+}=0.52, \mathrm{~Pb}^{2+}=0.31$ and $\mathrm{Cd}^{2+}=0.56 \mathrm{ppm}$. It Seems that at approximately a solid to liquid ratio of $50 \mathrm{~g} / \mathrm{L}$ provides a $99 \%$ adsorption ratio of $\mathrm{M}^{2+}$.

\subsection{Effect of solution pH on heavy metal Ions adsorption}

The effect of solution $\mathrm{pH}$ on $\mathrm{M}^{2+}$ ions adsorption was determined for the $\mathrm{pH}$ range of 2.0-11.0 which normally found, for example, in an electro kinetic soil reclamation process (e.g. Jih-Gaw and Kuo-Chung [13], Baes and Mesmer [14]) For this set of experiments, 11 samples of a 0.05 solid to liquid ratio were prepared with $40 \mathrm{ml}$ of total solution's amount. The samples were shaken for $2 \mathrm{~h}$ at $400 \mathrm{rpm}$. Sufficient $\mathrm{M}^{2+}$ salt was added to the suspension in order to make a $\left(10^{-3} \mathrm{M} / \mathrm{L}\right) \mathrm{M}^{2+}$ ions solution. $1.0 \mathrm{NaOH}$ and $\mathrm{HCL}$ were added to adjust the solution $\mathrm{pH}$ of each sample between 2.0 and 11.0. The residual $\mathrm{M}^{2+}$ concentration in solution were then determined by centrifugation and (AA) analysis of supernatants. It has been found, significant amount of $\mathrm{M}^{2+}$ ions adsorption in the $\mathrm{pH}$ range of $4.5-6.0$ with over $99 \%$ adsorption at a solution $\mathrm{pH}>8$. The adsorption density as a function of $\mathrm{pH}$ is plotted in figure 5 .

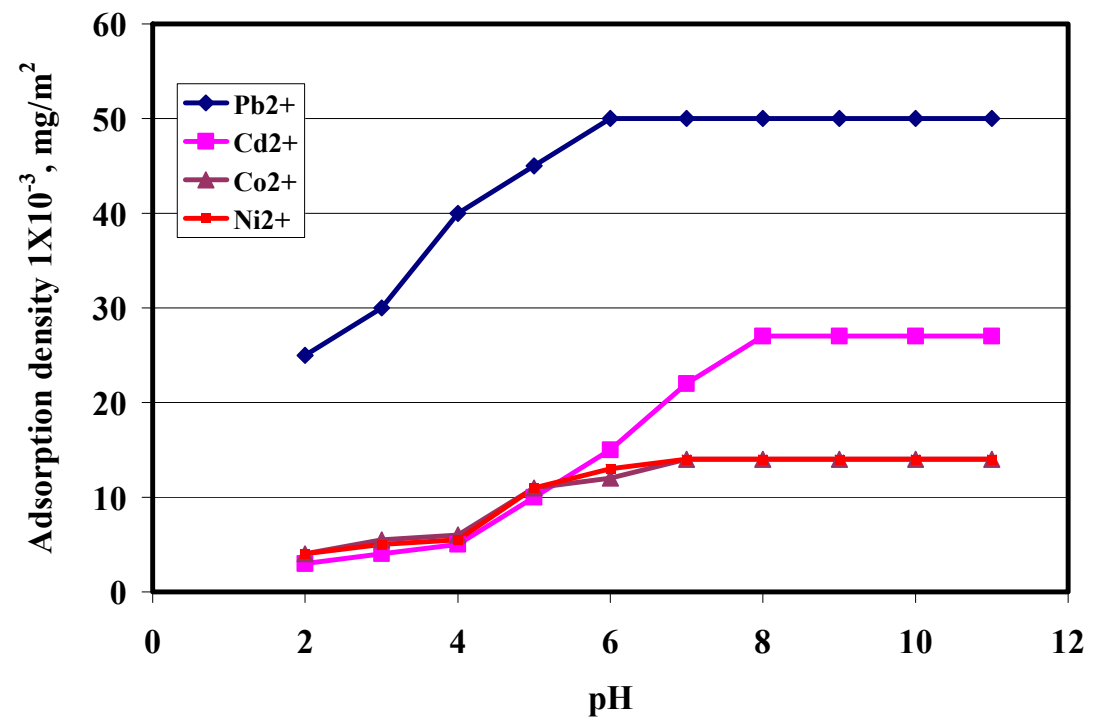

Figure 5: Effect of $\mathrm{pH}$ on adsorption density of $\mathrm{M}^{2+}$, onto Clay ( $\mathrm{S} / \mathrm{L}$ ratio $50 \mathrm{~g} / \mathrm{L}, \mathrm{C}_{\mathrm{i}}=2 \times 10^{-3} \mathrm{M} / \mathrm{L}, \mathrm{T}=20^{\circ} \mathrm{C}$, and conditioning time $2 \mathrm{~h}$ ). 
The experiment of heavy metal ion uptake by adsorbents showed a marked trend as follows: $\mathrm{Pb}^{2+}>\mathrm{Cd}^{2+}>\mathrm{Co}^{2+} \geq \mathrm{Ni}^{2+}$. It reveals that the absorbability by Clay independent on $\mathrm{pH}$. The double-layer theory predicts qualitatively correctly that the affinity of the exchanger for bivalent ions is larger that monovalent ions and that this selectivity for ions of higher valence decreases with increasing ionic strength of the solution. However, according to the Gouty theory should be no ionic selectivity of the exchanger between different equally charged ions.

\subsection{Effect of heavy metal ions concentration on adsorption onto clay}

For the concentration study, 10 separate $\left(2.10^{-3} \mathrm{M}\right.$ heavy metal ions) samples were prepared in the same manner described before. Each sample had a $50 \mathrm{~g} / \mathrm{L}$ solid to liquid ratio. Each sample was stirred at 180 strokes per minute for a different amount of heavy metal concentration ${ }^{-5}, 5 \times 10^{-4}, 10^{-3}, 2.5 \times 10^{-3}, 5 \times 10^{-3}$, $10^{-2}, 2.5 \times 10^{-2}, 5 \times 10^{-2}$, respectively. After being stirred for its designed concentration, the samples were collected in vials for analysis.

Figure 6: illustrates the adsorption of heavy metal ions as a function of residual concentration onto Clay. The adsorption isotherms in the figure 5 illustrates two distinct regions each characterized by different adsorption rates and mechanisms. In the first stage, the adsorption is very fast and takes place at a lower concentration which can be attributed to ion exchange process between the heavy metal ions and clay surface ions. In the second stage, the adsorption is mainly influenced by the interaction between adsorbed ions. However, the ion exchange process still continues to take place in a similar rate as the ion exchangeable ions release continues even in the plateau region.

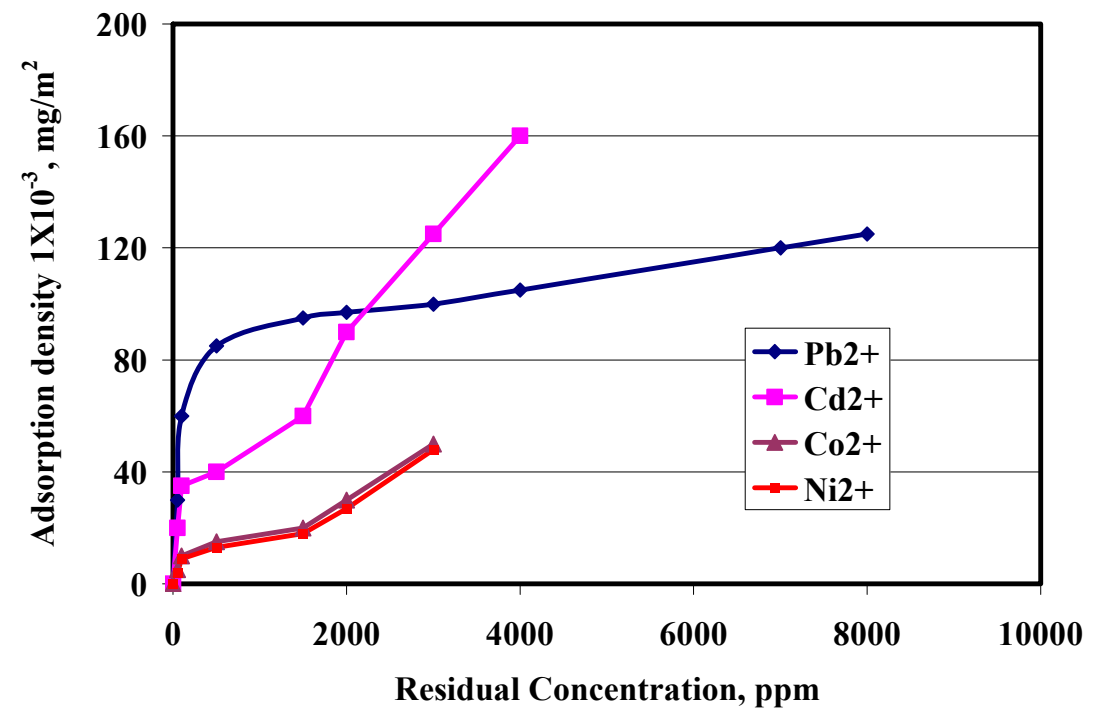

Figure 6: Effect of heavy metal concentration on adsorption density of $\mathrm{M}^{2+}$ onto clay. ( $\mathrm{S} / \mathrm{L}$ ratio $50 \mathrm{~g} / \mathrm{L}, \mathrm{T}=20^{\circ} \mathrm{C}$, and conditioning time $2 \mathrm{~h}$, and $\mathrm{pH} 4.8-7.6)$. 


\section{Conclusion}

Electrophoresis measurements (Zeta potential) of these studies indicated the adsorption of the hydrolysable metal toxic ions on the Clay surfaces.

The sorption study indicated that the heavy and toxic metals $\mathrm{Pb}$ (II), Ni (II), Co (VI) and Cd (II) could be adsorbed and thus removed significantly by Clay from aqueous solutions. The batch adsorption tests showed that the removal of metal ion by Clay is a fast process which can reach the equilibrium after 30 seconds. On the other hand, the adsorption increases with increasing the initial ions concentration and $\mathrm{pH}$. Kinetic modeling showed that the first-order model was appropriate for the description of this type of adsorption. The experiment of heavy metal ion uptake by adsorbents showed a marked trend as follows: $\mathrm{Pb}^{2+}>$ $\mathrm{Cd}^{2+}>\mathrm{Co}^{2+} \geq \mathrm{Ni}^{2+}$.

\section{Acknowledgements}

I would like to thank Prof H. El-Sall (Florida University, Gainesville, Florida, USA) for guiding and support throughout this research, also Eng. Nesren Khairy (GRA) for great help.

\section{References}

[1] Kara, M., Yuzer, H., Sabah, E., Celik, M. S., "Sepiolite as an adsorbent for elimination of mine wastes," Environmental Issues and Waste Management in Energy and Mineral Production 717, 1998.

[2] Haden Jr., W.L., Schwint, I. A., "Attapulgite - Its Properties and Applications"' Industrial and Engineering Chemistry, 59 (9), 59, 1967.

[3] Haden, W. L., "Attapulgite : Properties and Uses," in Proceedings of the $10^{\text {th }}$ National Conference on Clays and Clay Minerals, E. Ingerson, Ed., P.284, Pergamon Press, New York, 1963.

[4] S. E. Elmofty; "Beneficiation of bentonite from Kaolin Deposit in Aqueous Media by changing $\mathrm{pH}^{\text {"; }}$ Minerals Processing on the Verge of the $21^{\text {st }}$ Century, 2000.

[5] McCarter, W. S. W., Krieger, K. A., Heinemann, H., Ind. Eng.Chem.42, $529,1950$.

[6] Karston, W. A., "Adsorption and Catalysis," unpublished data, Minerals \& Chemicals Philipp Corp., Menlo Park, N.J., 1959.

[7] Hiemenz P.C., "Principles of colloidal and surface chemistry", Marcel Dekker, Inc, New York, 1977.

[8] H.S. Hanna and P. Somasundaran, "Physico-chemical Aspects of Adsorption at Solid/Liquid Interfaces, Part 2 - Mahogany Sulfonate/Berea Sandstone, Kaolinite System” in Improved Oil Recovery by Surfactant and Polymer Flooding, D.O. Shah and R.S. Schechter Eds., Academic Press: New York, 1977, p 253. 
[9] S.E. Elmofty, F.H. Ashour and H El-Shall; "Adsorption mechanism of toxic metal ions by Caly (Attapulgite)"; Twelfth International water technology conference, IWTC 12 2008, Alexandria, Egypt.

[10] Marc A. Anderson., Alan J. Rubin "Adsorption of inorganics at solid-liquid interfaces", Ann Arbor Science, 1981.

[11] Elmofty, S. E., P. Somasundaran and K.V. Viswanathan. " $\mathrm{Ca} / \mathrm{Mg}$ Enrichment of Dolomite Surface in Aqueous Solutions: Solid/Liquid Ratio and Mixing Time Effects," Min. Met. Proc., 6, pp. 96. (1989).

[12] Yalcın, M., Gürses, A., Doğar, C., Sözbilir, M., "The adsorption kinetics of cethyltrimethylammonium bromide (CTAB) onto powdered active carbon", Adsorption 10 (2004) 339-348

[13] Jih-Gaw, L., Kuo-Chung, W. "Characteristics of Heavy Metal Adsorption of River Bed Sludge Components" Toxicological and environmental Chemistry, Vol. 65, pp. 41-56.

[14] Baes, C.F., and R.E. Mesmer; "The hydrolysis of cations"; John Wiley \& Sons, Inc., New York 1976. 